\title{
COST ANALYSIS AND THEIR IMPACT IN DETERMINING THE PRICE LEVEL OF ELECTRICITY
}

\author{
J. Angelova* \\ Department of Economics, Industrial Engineering and Management, Faculty of Management, \\ Technical University of Sofia, Bulgaria
}

\begin{abstract}
The aim of the project is to review the state and development of prices for households and industrial consumers in the EU member states and to compare the final prices of electricity in Bulgaria with those of the other countries. Eurostat data is used for a period of eight years in order to make a comparative analysis as well as to reflect the types of costs that are formed in determining the prices of electricity for industrial and household consumers. In order to analyze the level of dependence of electricity prices and their comparability with the EU member states, a regression analysis is applied.
\end{abstract}

Key words: Electricity; Regression analysis; Trendy projection.

\section{INTRDUDCTION}

Electricity (EE) prices in the EU depend on a number of non-market factors such as geographic location, voltage level, hourly consumption bandwidth, cost of transmission and distribution of $\mathrm{EE}$, environmental costs, etc.

The tariff structure of prices is extremely diverse in different countries. Widespread multi-element tariff systems, including, for example, Tariff prices for power / availability, energy, connection, transmission, system services, etc. Additionally, tariff rates are differentiated by zone of the day, by seasons, by volume of consumption, by maximum consumption, etc.

\section{TYPES OF EXPENDITURE DETERMINING THE LEVELS OF EE}

The main types of costs that determine the level of EE prices for end-users in the EU are [6]:

-Expenses for EE production;

-Costs of joining and using the grid to transport the produced energy from producers to consumers;

-Payments (taxes, fees, surcharges, fines, etc.) imposed by governments and regulators on EE prices.

\footnotetext{
*Correspondence to: Assoc.Prof.Dr. Jordanka Angelova, Department of Economics, Industrial Engineering and Management, Faculty of Management, Technical University of Sofia, Bulgaria,e-mail: jsa@tu-sofia.bg
}

With the launch of the process of liberalization of the European electricity market, the socalled „Division of prices”, are being divided into:

- prices for EE production - energy component;

- prices for the use of the electricity grid - a network component;

- Payments imposed by governments and regulators on EE prices - a tax component [2].

When considering the tax component, it should be borne in mind that apart from VAT, EE prices also include other specific taxes, fees, surcharges, excise duties, etc. Typically, these specific tax payments are aimed at achieving environmental objectives or offsetting costs created by non-market liabilities in a functioning internal energy market, such as public service obligations, energy purchasing obligations generated by indigenous energy sources, RES or combined Production, nonrefundable costs - as a result of signed longterm fixed energy purchase contracts [4].

The specificity that is to be taken into account is that not all payments of a tax character are explicitly included in the final EE prices. In certain cases, such types of payments are included in the network tariffs or are paid by producers / suppliers. In other words, in a number of cases, they are not a direct or determinable component of the final prices but are included in the costs of the producers, the transmission company or the suppliers. As a result, this may lead to inaccurate estimates 
(overestimation) of the energy and network components.

A mandatory component of the tax component is the minimum rates for taxation of EEs and energy products introduced by Directive 2003/96 / EC [5]. The principle is the principle of excise duty in the Member State of destination of excise goods. At the same time, both double taxation and non-taxation are avoided, while at the same time allowing for flexible behavior by Member States in achieving their objectives by balancing competitiveness, sustainability and security of supply.

The networking component of prices is calculated through a wide range of tariffs and covers a number of cost categories performed by different companies and regulated by the relevant regulatory institutions.

An overview of the transmission network (HV and $\mathrm{CH}$ network) tariffs made by the European Commission (EC) shows significant differences between countries as follows $[5,6]$ :

- The transmission price is allotted either to users (L-component) or only to manufacturers (G-component) or mixed to users and manufacturers

- The transmission price is a onecomponent (energy price only) or consists of the energy component and the availability component ("power" in the EU terminology).

In turn, the ratio between the energy component and the availability component also varies over a wide range.

There is a wide variety of practices in different countries in relation to other tariff structures (seasonal, location, additional services, nonrefundable costs, etc.)

All costs that are not included in the network and tax component are included in the energy component. These are basically the costs of power plants and are usually linked to the prices at which suppliers buy EEs. The energy component has a dominant share in end-user prices for most countries.

\section{OVERVIEW AND ANALYSIS OF EE PRICES IN EU COUNTRIES}

The forthcoming review is related to the state and development of prices for household and industrial consumers in the EU Member States and the comparison of the final prices of EEs in Bulgaria with those of the other countries.

With a view to creating a comparability condition, the subject of the review is EE prices, brought to a total pay per kilowatt hour for:

* Households with an annual consumption of $3500 \mathrm{kWh}$;

* Industrial consumers with an annual consumption of $2500 \mathrm{MWh}$, according to Eurostat standards.

The benchmarking of EE prices for household customers covers an 8-year period from 2007 to 2014 .

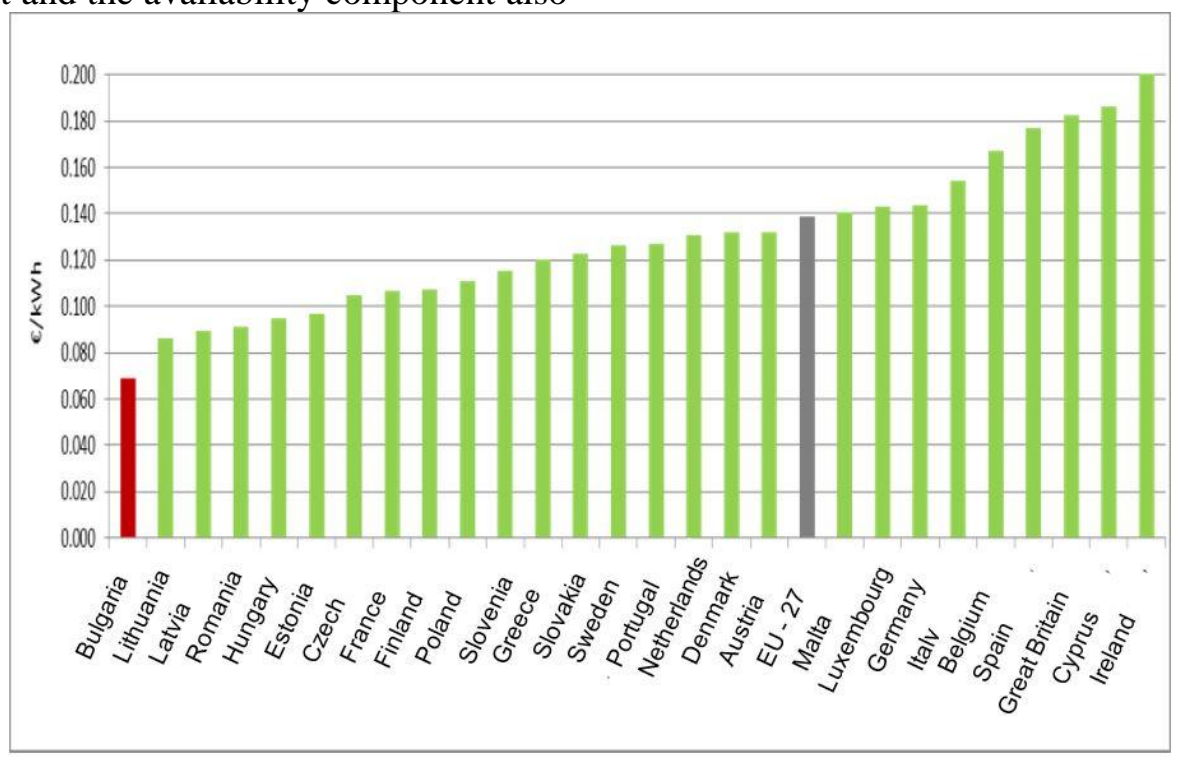

Figure 1. EE prices for residential users (Euro cent per kWh)

Source: Eurostat

According to Eurostat figures presented in Figure 1, the cost of $\mathrm{EE}$ for households in
Bulgaria for 2014 is $6.89 € / \mathrm{kWh}$. Excluding VAT, as it is the lowest among the $27 \mathrm{EU}$ Member States. For comparison this price is: 
- 50\% lower than the EU-27 average EU EED household cost, amounting to $13.88 € / \mathrm{kWh}$; - $66 \%$ lower than the highest house price - that in Ireland, amounting to $20.08 € \mathrm{c} / \mathrm{kWh}$;
ANGELOVA J.

- $24 \%$ lower than in Romania, amounting to $9.01 € \mathrm{c} / \mathrm{kWh}$

The benchmarking of EE prices for industrial users covers an 8-year period from 2007 to 2014.

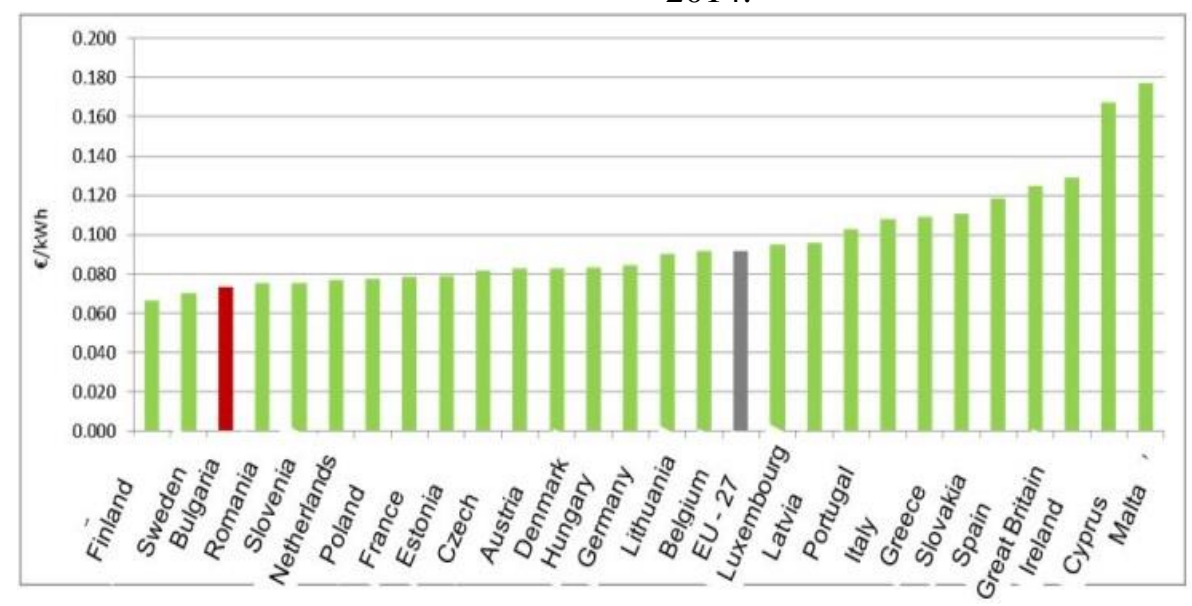

Figure 2. EE prices for industrial users (Euro per $\mathrm{kWh}$ ) Source: Eurostat,

According to Eurostat data, the figures presented in Figure 2, the price of EE for a standard industrial user for 2014 in Bulgaria excluding taxes is $7.36 € / \mathrm{kWh}$ and is higher than in Finland and Sweden. For comparison this price is:

- $11 \%$ higher than in Finland, amounting to $6.64 € / \mathrm{kWh}$;

- $20 \%$ lower than the aggregate average EE price for the E-27 industry, amounting to 9.17 $€ \mathrm{c} / \mathrm{kWh}$;

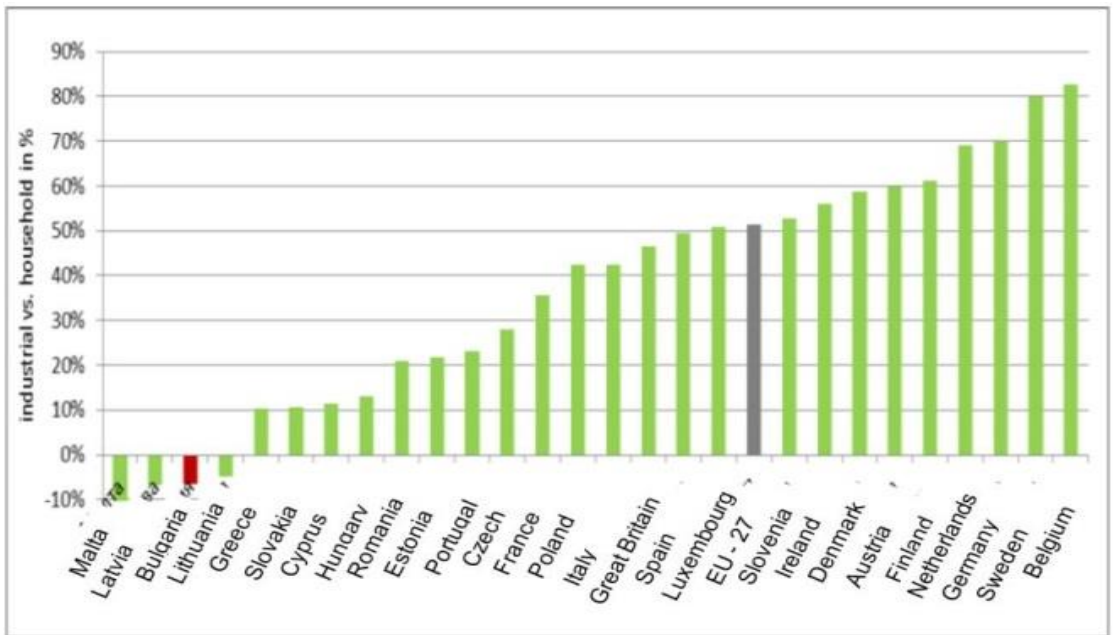

Figur 3. Price ratios (household and industry) excluding taxes and charges, in $\%$. Source: Eurostat,

From Figure 3. it is clear that EE prices for the EU27 countries are 51\% higher than the industry prices. This standard ratio is derived from two major factors: the higher cost of network services to household consumers due to their joining to low-voltage grids and higher energy costs $(\mathrm{kWh})$ due to the specificity of household consumption, Unstable and with
- 58\% lower than the highest cost for a business user - that in Malta, amounting to $€$ $17.70 \mathrm{c} / \mathrm{kWh}$;

The above figures show that the higher energy prices for industry have achieved greater convergence between average European and local average than household prices. larger fluctuations in 24-hour and seasonal cut compared to industrial. For Bulgaria this ratio is much lower and with years decreasing: from $17.6 \%$ at 2007 prices, $7.8 \%$ from 2011 prices and from 2014 prices is negative, reaching $-6 \%$

By itself, such a deviation from standard ratios indicates that there is cross subsidy to households. Cross-subsidization, which is 
obviously deepening instead of being overcome, besides being contrary to the basic pricing principles introduced in Bulgarian legislation, can create serious problems with the maintenance and modernization of lowvoltage networks, respectively with the security of electricity supply Households, on the one hand, and become a difficult barrier to the liberalization of the internal electricity market after the outbreak of medium and low tension on the other.

From the comparative analysis made so far, the similarities and differences in the prices of $\mathrm{EE}$ between the different countries in the EU, the averages for the EU and those of Bulgaria were established.

\section{ANALYSIS OF THE CHANGE OF PRICES BY TREND PROJECT}

In order to analyze and forecast price movements, it is necessary to use statistical methods of analysis [8].

In this study, household prices will be analyzed on average for the 27 member states of the European Union - EU-27 and those in Bulgaria.

Table 1. EE household prices in EUR per $k W h$

\begin{tabular}{|l|c|c|c|c|c|c|c|c|}
\hline Year & 2007 & 2008 & 2009 & 2010 & 2011 & 2012 & 2013 & 2014 \\
\hline EU - 27 & 0,1173 & 0,1177 & 0,1224 & 0,1221 & 0,1281 & 0,1338 & 0,1372 & 0,1388 \\
\hline BG & 0,0547 & 0,0593 & 0,0685 & 0,0675 & 0,0688 & 0,0706 & 0,0771 & 0,0689 \\
\hline
\end{tabular}

Table 1 shows that there has been steady growth over the years.

With the help of the Trend Projection Method [3], the price change can be analyzed and predicted by focusing on finding a linear A function that predicts the trend, namely: $Y_{t}=\alpha+\beta_{t}$

Where:

$Y_{t}$ - the value of the EE price;

$\mathrm{t}$ - time in years;

$\alpha, \beta$ - parameters of the equation.
The value of the parameters of the equation is calculated by the least squares method. [1] After the calculations, the function of the straight line takes the form of:

$$
\mathrm{Y}(\mathrm{EC} 27)=0.130606+0.003431 \mathrm{t}
$$$$
\mathrm{Y}(\text { Bulgaria })=0.069258+0.002333 \mathrm{t}
$$

Based on the calculations made in Figure 4, the trend projection is presented and the development of prices in perspective until 2018 is considered.

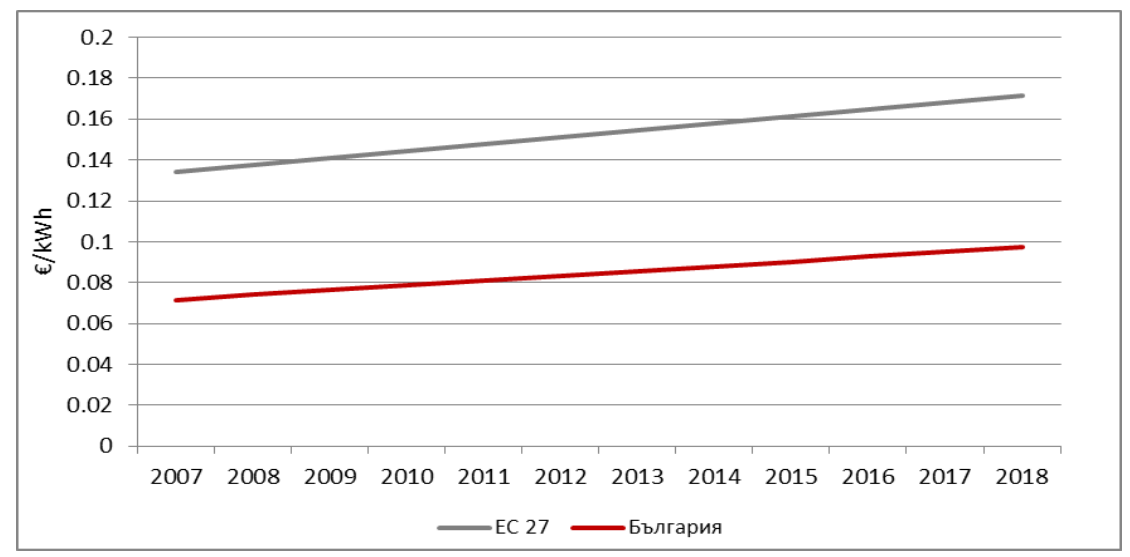

Figure 4. Rights of the trend projection for household prices in the EU-27 and in Bulgaria

There is a general trend of growth, with the lines almost parallel. The line for Bulgaria is weaker.

In order to analyze the level of dependence it is necessary to use another statistical method regression analysis. The baseline data on EEE prices will be used on average for the EU-27 countries and for Bulgaria for the analyzed period.
EU-27 data is the independent component and the data for Bulgaria is dependent.

Detailed calculations were made in Excel using the Regression function and complete regression statistics were made. The summary result of the regression analysis is presented in Table 2. 
Table 2. Regression statistics

\begin{tabular}{ll}
\hline Regression Statistics/ Регресионна статистика \\
\hline Multiple R & 0.802308471 \\
R Square & 0.643698883 \\
Adjusted R Square & 0.584315363 \\
Standard Error & 0.005536773 \\
Observations & 8 \\
\hline
\end{tabular}

The Multiple R correlation coefficient equals 0.802308 . This shows that there is a strong correlation between EE prices in Bulgaria and those in the European Union.

The level of dependency is determined by the determination coefficient ( $\mathrm{R}$ Square), which is equal to 0.643698 . This means that $64 \%$ of the household energy EE price is influenced by the price of $\mathrm{EE}$ in $\mathrm{EU} 27$, the remaining $36 \%$ by other factors.

In the price analysis for the industry, price data is again used in the EU27 and in Bulgaria for the same 8-year period.

Table 3. Energy Efficiency Prices in EUR per $k W h$

\begin{tabular}{|l|l|l|l|l|l|l|l|l|}
\hline Years & 2007 & 2008 & 2009 & 2010 & 2011 & 2012 & 2013 & 2014 \\
\hline EU - 27 & 0,0820 & 0,0879 & 0,0954 & 0,0916 & 0,0934 & 0,0957 & 0,0940 & 0,0917 \\
\hline BG & 0,0465 & 0,0557 & 0,0639 & 0,0639 & 0,0638 & 0,0684 & 0,0803 & 0,0736 \\
\hline
\end{tabular}

Price dynamics is observed over the years, so the Sliding Average method will apply here. The trend projection is presented in Figure 5.

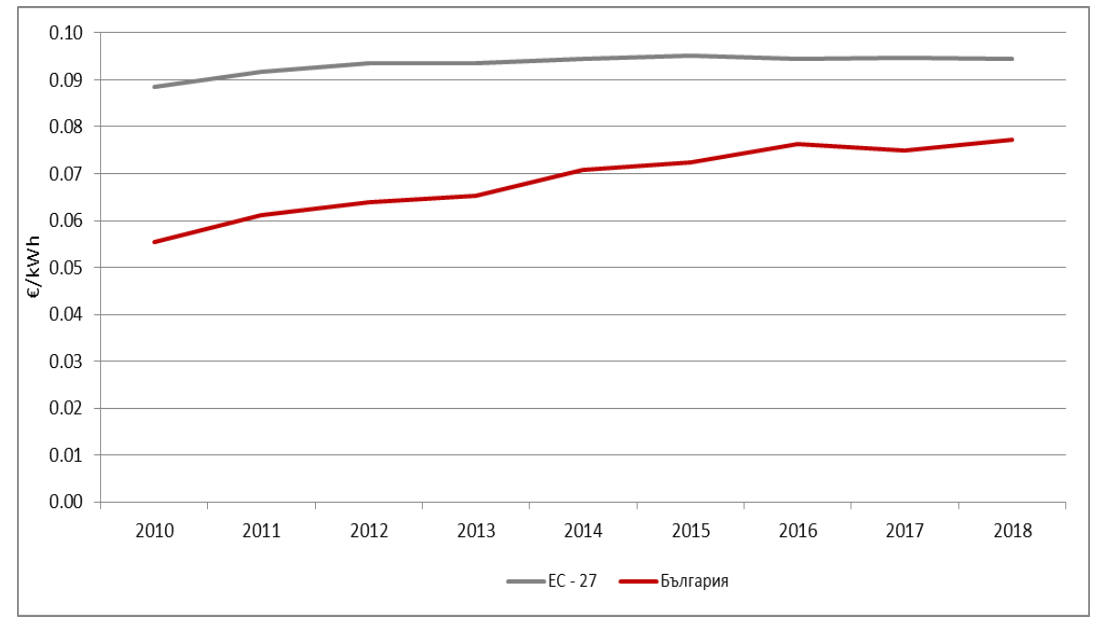

Figure 5. Rights of the trend projection for industrial prices in the EU-27 and in Bulgaria

Again, there are quite similar graphs, so the regression analysis method will be applied.
The summary of the analysis is presented in

\section{Table 4.}

Table 4. Regression analysis

\begin{tabular}{ll}
\hline \multicolumn{2}{c}{ Regression Statistics / Обобщен резултат } \\
\hline Multiple R & 0.775554891 \\
R Square & 0.601485389 \\
Adjusted R Square & 0.535066287 \\
Standard Error & 0.003113591 \\
Observations & 8 \\
\hline
\end{tabular}

The correlation coefficient (Multiple R) equals 0.77555 , which shows a strong correlation between the prices for the Bulgarian industry and the average for the EU - 27. 
The level of dependency is determined by the determination coefficient (R Square), which equals 0.60149 . This means that $60 \%$ of the $\mathrm{EE}$ price for the Bulgarian industry is influenced by the price of EE in the EU27, the remaining $40 \%$ of other invoices.

\section{CONCLUSION}

The price of electricity in Bulgaria for household consumers is the lowest in the EU, due to cross-subsidization at the expense of the industry. Cross-subsidization, which is obviously deepening instead of being overcome, besides being inconsistent with basic pricing principles, can create serious problems with the maintenance and modernization of low-voltage networks and the security of household electricity supply respectively. It can also become a difficult barrier to the liberalization of the internal electricity market after the middle and low tensions have elapsed.

This also explains why EE's industry prices are close to average European prices. There is a direct link between the price changes in the EU and Bulgaria, and this is most evident in industrial prices. The fact is that the market opened sharply, and by July 2014 only the household and business users of LV remain on the regulated market.

Although for the large, medium and small business market has been liberalized, some of the price remains regulated by the CBRN. This is the network component, the share of which grows inexplicable for consumers with the "debt to society" component introduced in recent years.

\section{REFERENCES}

1. Adamov., V. Holst Dj./ Finansov analiz, Abagar, V.Tarnovo, 2006;

2. Angelova J., Opredeljane cenata na elektricheskata energja, king, Sofia, 2008;

3. Chris Harris, Electricity Markets: Pricing, Structures and Economics, Wiley Finance, May 2006;

4. Deneva.,A., R.Angelova, Finansirane na proekti za vazobnovjaemi energiini iztochnici - sastojanie i problemi, Industrialen menidjmant, Technical university -Sofia, N1, pp.60-73, ISSN 1312-3793;

5. Direktive/96/EU of Europian parliament and Counsil 26.06.2003, on common rules for the internal market in Power Electricity and repealing Directive 96/92 / EU;

6. Metodika za opredeljane cenite na balansirashtata, Prilojenie kam chlen 105, al. 4 ot Pravilata za targovia s elektricheska energia, DV. Br. 39/05.2014

7. Naredba № 1/14.03.2017 $г$ za regulirane cenite na elektricheskata energia]

8. Velichkova N., I.Kacarska, Prilojenie na regresionnia i korelacionnia analiz pri modelirane na ikonomicheski procesi, Technika, S., 2006. 
ANGELOVA J. 